\title{
UV radiation evokes negative phototaxis and covering behavior in the sea urchin Strongylocentrotus droebachiensis
}

\author{
Nikki L. Adams* \\ Department of Biological Sciences, 5751 Murray Hall, University of Maine, Orono, Maine 04469, USA
}

\begin{abstract}
Intertidal and subtidal Strongylocentrotus droebachiensis (Müller) often hide among rocks or cover themselves with debris, including macroalgae, mussel shells, and pebbles. Similar reactions in other species of sea urchins have been interpreted as a response to bright sunlight. This study examined the response of $S$. droebachiensis specifically to ultraviolet radiation (UVR). In laboratory studies using artificial irradiation, S. droebachiensis exposed to UVR (290 to $400 \mathrm{~nm}$ ) and photosynthetically active radiation (PAR, 400 to $700 \mathrm{~nm}$ ) sought shade and covered themselves significantly more frequently than those exposed only to PAR. In outdoor aquaria, individuals were exposed to ambient solar radiation that was filtered to create 4 treatments (dark, PAR, PAR + UVA, or PAR + UVA + UVB) and observed for $6 \mathrm{~h}$ as total solar irradiance changed with time of day. Sea urchins covered themselves with significantly more material when exposed to PAR + UVA + UVB than in all other treatments, and in response to total irradiance. The amount of covering by sea urchins exposed to PAR + UVA (320 to $400 \mathrm{~nm}$ ) varied over the course of the day, but were typically less than those exposed to UVB (295 to $320 \mathrm{~nm}$ ). These sea urchins covered themselves more than those exposed to PAR alone or held in the dark. Sea urchins exposed to PAR alone did not differ in the amount of covering from those held in the dark, regardless of time of day. The amount of covering correlated significantly with UVB and UVA irradiance independently, but not PAR irradiance. This study does not rule out that multiple cues may cause the covering response, but it demonstrates that $S$. droebachiensis seeks shelter and covers itself in response to UVR, primarily UVB wavelengths or a combination of UVA and UVB, presumably to avoid UV-induced damage.
\end{abstract}

KEY WORDS: Sea urchins $\cdot$ Covering behavior $\cdot$ Ultraviolet radiation

\section{INTRODUCTION}

Many shallow-dwelling invertebrates such as sea anemones, sea cucumbers, and sea urchins adorn themselves with debris from their surroundings (reviewed by Millott 1975, Dykens \& Shick 1984, Clouse 1997), a behavior referred to as the 'covering,' 'heaping,' 'burying,' or 'hatting' response. This activity has been studied most extensively in the sea urchin Lytechinus

\footnotetext{
*Present address: The Marine Science Institute, University of California, Santa Barbara, California 93106, USA.

E-mail: n_adams@lifesci.ucsb.edu
}

variegatus (Millott 1955, 1956, Sharp \& Gray 1962), but has also been documented in many other species of sea urchins from polar, e.g., Sterechinus neumayeri (Dayton et al. 1970); temperate, e.g., Lytechinus anamesus (Lees \& Carter 1972), Psammechinus milaris (Lindahl \& Runnström 1929, Mortensen 1943), Evechinus chloroticus (Dix 1970), Strongylocentrotus purpuratus (Douglas 1976), S. lividus (Dubois 1914), and Sphaerechinus sp. (von Uexkull 1887); and tropical regions, e.g., Tripneustes esculentus (Lewis 1958, Moore et al. 1963).

Controversy surrounds covering behavior in sea urchins and arises from conflicting reports that Millott 
(1975) attributes to the oversimplified explanation of a complex behavior given by studying one aspect at a time. Covering by sea urchins may be a means of avoiding predators (Milligan 1915, Boone 1925, Dayton et al. 1970). The only convincing evidence for this hypothesis was provided by Dayton et al. (1970), who demonstrated that the predatory sea anemone Urticinopsis antarctica releases the Antarctic sea urchin Sterechinus neumayeri when it is covered with stinging hydroids. In contrast, covering has been correlated with the availability of drift material and hypothesized to be a means of holding food prior to its consumption or epithelial digestion of organic films (Péquigant 1966, Dix 1970, Douglas 1976). This hypothesis is plausible, but does not explain why sea urchins cover themselves with indigestible materials.

Alternatively, covering may provide protection against physical factors such as high temperatures and desiccation (Orton 1929), or it may serve as ballast to protect against displacement by wave action (Lees \& Carter 1972). Nevertheless, many of the species of sea urchins that cover themselves live subtidally and are not at risk of desiccation or severe turbulence, and the debris they hold makes them top-heavy and unstable (Millott 1975). This response could be an automatic reflex or byproduct when moving through shell covered substrates (Dambach \& Hentschel 1970). However, evidence demonstrating phototaxis, the photosensitivity of tube feet and photic spine responses argue that this behavior is a deliberate action (Millot 1975).

The best-supported hypothesis is that sea urchins cover themselves in response to sunlight (Lindahl \& Runnström 1929, Mortensen 1943, Millott 1956, Lewis 1958, and others reviewed in Millot 1975), specifically ultraviolet radiation (UVR, 295 to $400 \mathrm{~nm}$ ) (Sharp \& Gray 1962, Lees \& Carter 1972). Many sea urchins display negative phototaxis to strong sunlight by hiding among rocks and vegetation or by moving into areas where the light is less intense (Holmes 1912, Sharp \& Gray 1962). Moreover, Millott (1956) conclusively showed that Lytechinus variegatus covers itself in response to bright sunlight by demonstrating that $L$. variegatus used coordinated movements among its tube feet and spines to move stones along its body to track a beam of sunlight shone anywhere on its epidermis. These observations were repeated by Lewis (1958) using Tripneustes esculentus. Sea urchins typically cover themselves diurnally when they are exposed to the brightest levels of sunlight, and drop the covering at night (Millott 1956, Sharp \& Gray 1962). Other investigators have noted that some sea urchins (e.g., Strongylocentrotus purpuratus), do not drop their covering at night, indicating there may be multiple cues inducing covering (Douglas 1976). Nevertheless, sea urchins may cover themselves in response to UV wavelengths of sunlight that induce cellular damage in many aquatic organisms.

Sharp \& Gray (1962) provided some of the first evidence that artificial UVR can induce covering in Lytechinus variegatus. Although they did not provide the emission characteristics of their lamps, they demonstrated that the covering reaction was diminished when they filtered out wavelengths below $295 \mathrm{~nm}$. Later studies specifically showed that UVC $(254 \mathrm{~nm})$ induces covering in sea urchins and eventually kills them (Lees \& Carter 1972). However, stratospheric oxygen and ozone absorb wavelengths below $295 \mathrm{~nm}$ (Madronich et al. 1998). Experiments exposing sea urchins to natural solar radiation indicated that UVA ( 320 to $400 \mathrm{~nm}$ ) or UVB (295 to $300 \mathrm{~nm}$ ) wavelengths may induce covering (Sharp \& Gray 1962, Lees \& Carter 1972). Unfortunately, these experiments did not examine the role of photosynthetically active radiation (PAR, 400 to $700 \mathrm{~nm}$ ) alone or remove interacting effects of changes in light intensity with and without UVR.

Thus, whether covering by sea urchins is in part a response to total photon flux or to specific wavelengths of light such as PAR, UVA, and UVB wavelengths remains to be determined. It is particularly important to understand how sea urchins respond to UVR that penetrates into seawater (Booth \& Morrow 1997) because phototaxis and covering behaviors may affect the distribution of sea urchins. Owing to stratospheric ozone depletion, unweighted levels of UVB have increased up to $7 \%$ in mid-latitudes of the northern hemisphere, $22 \%$ in the Arctic, and $130 \%$ in Antarctica since 1970, making it important to understand how organisms respond to changing levels of potentially deleterious UVR (Madronich et al. 1998). UVR can penetrate to at least $20 \mathrm{~m}$ in clear oceanic waters (Jerlov 1950, Booth \& Morrow 1997). In addition, UVB can penetrate to at least $3 \mathrm{~m}$ and UVA to at least $6 \mathrm{~m}$ in coastal Maine waters (Adams et al. 2001). Therefore, experiments were undertaken to determine whether the sea urchin Strongylocentrotus droebachiensis undergoes positive or negative phototaxis and covers itself in response to UVR.

\section{MATERIALS AND METHODS}

Collection of sea urchins. Strongylocentrotus droebachiensis (50 to $70 \mathrm{~cm}$ diameter) were collected by scuba divers from 10 to $15 \mathrm{~m}$ depth at Crow Island, Maine, and transported to the Darling Marine Center in May 1998 for laboratory experiments, and in September 1998 for solar exposure experiments. They were held indoors in aquaria with flowing seawater at 
ambient temperatures with no exposure to UVR for $1 \mathrm{wk}$ prior to experiments.

Laboratory experiments. UV exposures were performed using 4 banks of 4 UVA-340 lamps (Q-Panel Industries; see Adams et al. [2001] for emission properties of the lamps) and PAR illumination from Coolwhite F40 lamps (in fixtures with covers) suspended above indoor aquaria with flowing seawater. Control (unirradiated) replicates were exposed only to Coolwhite F40 lamps (Sylvania) with plastic covers, as a source of PAR light only. Doses of UVA and UVB were measured using International Light model SUL033 UVA and model SUL240 UVB underwater sensors having peak sensitivities at 350 and $295 \mathrm{~nm}$, respectively. PAR was measured using a Li-Cor LI-185B quantum photometer and LI-190SB quantum sensor. Quantum measurements of PAR were converted to radiometric units using the conversion factor $\left(4.6 \mu \mathrm{mol} \mathrm{m} \mathrm{m}^{-2} \mathrm{~s}^{-1}=1 \mathrm{~W} \mathrm{~m}^{-2}\right)$ for fluorescent lamps (McCree 1983). Control sea urchins experienced fluences of $\mathrm{PAR}=4.6 \mathrm{~W} \mathrm{~m}^{-2}$, $\mathrm{UVA}=0.011 \mathrm{~W} \mathrm{~m}^{-2}$, and $\mathrm{UVB}=0 \mathrm{~W} \mathrm{~m}^{-2}$, whereas UVexposed sea urchins experienced fluences of $\mathrm{PAR}=$ $4.5 \mathrm{~W} \mathrm{~m}^{-2}, \mathrm{UVA}=10.5 \mathrm{~W} \mathrm{~m}^{-2}$, and $\mathrm{UVB}=0.10 \mathrm{~W} \mathrm{~m}^{-2}$ during the experiments. An extremely low fluence of PAR compared with ambient levels (see below) was used in these experiments to test specifically for effects of UV wavelengths, not the total intensity of predominantly visible light.

Phototaxis: Eight aquaria $(76 \times 61 \times 16 \mathrm{~cm})$ with flowing seawater at $10 \pm 2{ }^{\circ} \mathrm{C}$ were divided with opaque covers to create dark and light halves. The direction of water flow varied randomly among aquaria. Four aquaria were exposed to PAR + UVR and the other 4 were exposed to PAR without any UV irradiation. Eight sea urchins were placed in the center of each aquarium along the interface between light and dark. The location of each sea urchin was noted every $30 \mathrm{~min}$ for $3 \mathrm{~h}$.

Covering response: Sea urchins were placed randomly in each of 12 aquaria with flowing seawater at $10 \pm 2{ }^{\circ} \mathrm{C}$. The bottom of each aquarium was covered with opaque plastic beads (1 $\mathrm{cm}$ diameter) that were handled easily by the sea urchins and provided a suitable substrate for covering. The beads were uniform pieces of inert material that enabled quantification of the covering response, but would not provide chemosensory cues. Five sea urchins were placed in each aquarium and exposed to 1 of the 3 treatments: (1) Dark, covered with an opaque lid; (2) PAR, exposed to Coolwhite F40 lamps only; (3) PAR + UVR, exposed to UVA-340 lamps ( $\mathrm{N}=4$ tanks). The beads on each sea urchin were counted every $30 \mathrm{~min}$. Lids covering dark aquaria were lifted slightly for less than $1 \mathrm{~min}$ to count the number of beads held by the sea urchins, so that these remained shaded during the counting. The number of beads on each sea urchin within an aquar- ium was averaged for all 5 sea urchins to obtain a mean for each replicate.

Effects of solar radiation on the covering response. Sea urchins were placed in outdoor aquaria $(76 \times 61 \times$ $16 \mathrm{~cm}$ ) overnight. On the morning of the experiments, 16 nearly opaque plastic boxes $(29 \times 16 \times 11 \mathrm{~cm})$ were distributed among 4 outdoor aquaria (4 boxes in each aquarium). The bottom of each box was covered with plastic beads. Five sea urchins were placed in each box and exposed to 1 of 4 light treatments created using plastics to filter solar radiation. Transmission cutoffs for each plastic are defined as the wavelength where $50 \%$ of the maximal value is transmitted. The treatments were as follows: (1) Dark, covered with opaque lid; (2) PAR, covered with Plexiglas ${ }^{\circledR} \mathrm{G}$ UV-opaque acrylic (50\% transmission at $400 \mathrm{~nm}) ;$ (3) PAR + UVA, covered with Mylar ${ }^{\circledR}$ Type D fluoropolymer film (50\% transmission at $320 \mathrm{~nm}$; or (4) PAR + UVA + UVB, covered with Plexiglas ${ }^{\circledR} \mathrm{G}$ UF-3 UV-transparent acrylic (50\% transmission at $295 \mathrm{~nm})(\mathrm{N}=4$ for each treatment, with 5 individuals in each treatment). These materials are commonly used in photobiological experiments (Gulko et al. 1995) to examine the role of specific wavebands of light and also to standardize the levels of PAR used in the experiments because the ratios of PAR to UVR wavelengths may affect physiological responses to UVR (Cullen \& Neale 1997). The 50\% transmission cutoff for Mylar ${ }^{\circledR} \mathrm{D}$ is $320 \mathrm{~nm}$, yet small amounts of radiation between 310 and $320 \mathrm{~nm}$ are transmitted (from $50 \%$ at $320 \mathrm{~nm}$ to $0 \%$ transmission at $310 \mathrm{~nm}$ ) through this material. Similarly, a small amount of UVA (from $50 \%$ at $400 \mathrm{~nm}$ to $0 \%$ at $380 \mathrm{~nm}$ ) is transmitted through UV-opaque acrylic. Therefore, UVA and UVB irradiances were measured every hour using the sensors and radiometer described previously, and PAR irradiance was measured using a Li-Cor model LI-1400 data logger and model LI-193SA spherical quantum sensor having sensitivity between 400 and $700 \mathrm{~nm}$. Quantum measurements of PAR were converted to radiometric units using the conversion factor $\left(4.6 \mu \mathrm{mol} \mathrm{m} \mathrm{m}^{-2} \mathrm{~s}^{-1}=1 \mathrm{~W} \mathrm{~m}^{-2}\right)$ for ambient sunlight described by McCree (1983) and Kirk (1994). The number of beads held by each individual was counted hourly from 10:00 to 16:00 h Eastern Standard Time. The water in boxes was exchanged hourly to keep dissolved oxygen at ambient levels. This displaced some beads from the sea urchins, so all beads were removed each hour and sea urchins were allowed to collect them anew.

Statistical analysis. Results of the phototaxis experiments were analyzed using a split-plot analysis of variance (ANOVA), to assess variation among treatments over time and to determine whether there were any interactions between treatments and tanks. Percentage data were arcsine-transformed for analysis. 
Covering data from experiments using artificial UVR were analyzed using a repeated measures ANOVA to assess variation among treatments over time and to determine whether there were any interactions between treatments and time. The number of beads per individual for each replicate was calculated as a mean for all sea urchins within one aquarium. The number of beads per individual in outdoor covering experiments were compared using a repeated measures ANOVA to determine whether covering varied among light treatments over time and whether there were interactions between light treatments and time. Treatments were blocked across aquaria to control for differences among tanks. A significant ANOVA was followed by a Student-Newman-Keuls (SNK) test at a significance level of 0.05 to detect differences among individual light treatments. Planned comparisons (a priori) tested the interacting effects of light treatment and time at $\alpha=0.05$.

Multiple regression analysis was used at a significance level of 0.05 to determine whether the number of beads per sea urchin correlated with UVB, UVA, or PAR individually in natural sunlight. Levels of PAR, UVA and UVB were taken from each treatment over time and compared to the number of beads held by sea urchins exposed to those treatments at those times, allowing a comparison between the amount of covering and the intensity of PAR, UVA, or UVB. Simple linear regression analysis was not appropriate because it

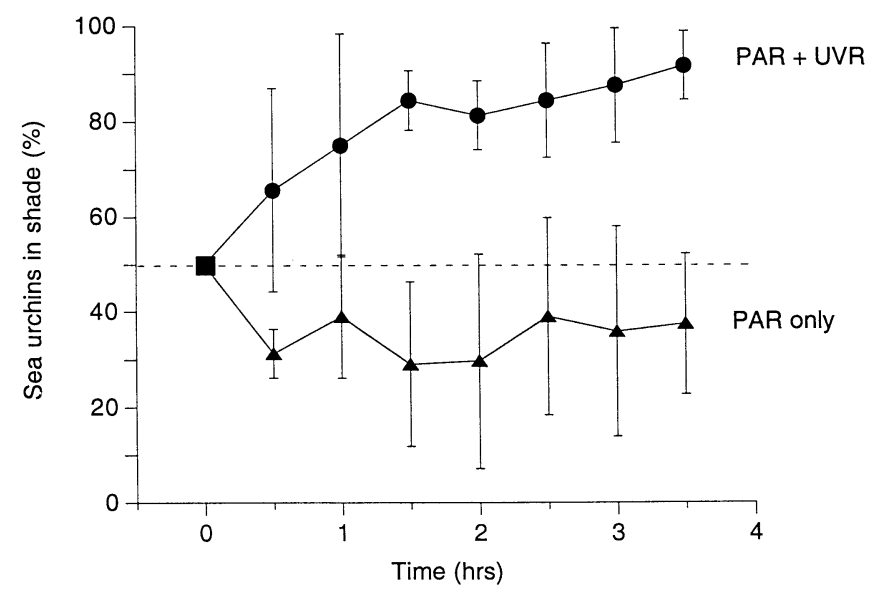

Fig. 1. Strongylocentrotus droebachiensis. Percent of individuals $( \pm \mathrm{SD})$ exposed to UVR that moved into the shade. Sea urchins started at the interface between light and dark (ם). A significantly greater percentage of sea urchins that were exposed to PAR + UVR (•) moved to shade than did those exposed to PAR alone $(\boldsymbol{\Delta})(\mathrm{p}<0.001$, split-plot ANOVA, $\mathrm{N}=$ 4). There was no significant effect of time on movement ( $p>$ 0.05), but there was a significant interaction between time and light treatments ( $\mathrm{p}=0.045)$, owing to rapid movement of individuals exposed to UVR into the shade within the first hour was not possible to expose sea urchins to UVB without simultaneously exposing them to UVA and PAR or to expose sea urchins to UVA without exposing them to PAR. In contrast, multiple regression analysis allows one to determine whether a dependent variable varies with individual independent variables by holding constant the variation due to the other independent variables (Zar 1999).

\section{RESULTS}

\section{Laboratory experiments}

Phototaxis

The percentage of sea urchins that sought shelter was significantly greater for those exposed to UVR than for those exposed to PAR only (Fig. 1 ; p $<0.01$ ). Time did not affect the number of sea urchins seeking shelter $(p>0.05)$, but there was a significant interaction between time and UV-treatment $(\mathrm{p}<0.05)$. Planned comparisons indicated that sea urchins exposed to PAR + UVR moved quickly to shelter during the first hour of the experiment $(p<0.05)$. The number of sea urchins under shelter remained constant from the first hour through the remainder of the experiment $(\mathrm{p}<0.05)$. In contrast, sea urchins exposed to PAR alone moved back and forth between the light and dark areas more frequently than those exposed to PAR + UVR, and were neither significantly negatively or positively phototactic at any time during the experiment $(\mathrm{p}>0.05)$.

\section{Covering response}

The number of beads held per individual was used as a measure of the degree of covering. The amount of covering varied by light treatment $(p<0.01)$. Sea urchins that were exposed to PAR + UVR covered themselves with more beads than did those exposed to PAR only and those held in the dark (Fig. 2; p $<0.05$, $\mathrm{SNK}, \mathrm{N}=4$ ). There was no difference in the mean number of beads held by sea urchins exposed to PAR only and those held in the dark ( $p>0.05$, SNK). Similarly, there was no relationship between time and the number of beads on sea urchins ( $p>0.05$ ), but there was an interaction between light treatments and time on the degree of covering $(p<0.05)$. Sea urchins exposed to UVR responded with a rapid increase in the number of beads held during the first hour (Fig. 2; p $<0.001$, planned comparisons). The number of beads they held remained the same from the first hour to the end of the experiment (Fig. 2 ; p > 0.05, planned comparisons). 


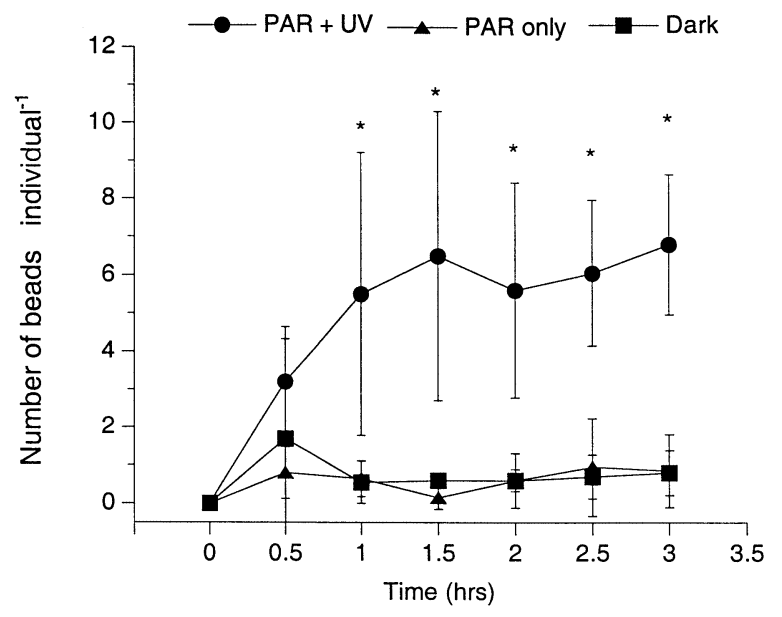

Fig. 2. Strongylocentrotus droebachiensis: The number of beads held per individual in response to light treatments. Sea urchins that were exposed to PAR + UVR (•) covered themselves with significantly more beads $( \pm \mathrm{SD})$ than did those that were exposed to PAR only $(\boldsymbol{\Delta})$ or held in the dark $(\boldsymbol{\square})(\mathrm{p}<0.05$, SNK, N = 4). ${ }^{*}$ Significant difference in the number of beads held by individuals exposed to PAR + UVR compared to the 2 other treatments

\section{Effects of solar radiation on the covering response}

The mean number of beads on sea urchins differed among light treatments (Fig. $3 ; \mathrm{p}<0.001$ ) and time of day $(\mathrm{p}<0.01)$. Similarly, there was a significant interaction between UV-treatment and time of day (or irradiance) $(\mathrm{p}<0.01)$. Individuals that were exposed to solar UVR covered themselves in response to the instantaneous amount of UVR they experienced over the treatments and the course of the day.

Sea urchins covered themselves with significantly more beads when exposed to PAR + UVA + UVB than in all other treatments (Fig. 3 ; p < 0.05, SNK). Individuals exposed to PAR + UVA covered themselves with significantly more beads than did sea urchins exposed to PAR alone or sea urchins held in the dark ( $p<0.05$, SNK). The amount of covering by sea urchins exposed to PAR alone did not differ from that by sea urchins held in the dark ( $p>0.05$, SNK).

Planned comparisons were used to detect differences among treatments at specific times of the day. Sea urchins held similar numbers of beads among treatments at 11:00 h, $1 \mathrm{~h}$ after the start of the experiment (Fig. $3 ;$ p > 0.05). Sea urchins exposed to PAR held the same number of beads as sea urchins kept in the dark ( $p>0.05$ for all time points). By 12:00 $h$, sea urchins exposed to PAR + UVA + UVB held significantly more beads than all other treatments $(p<0.05)$.
Sea urchins exposed to PAR + UVA had numbers of beads intermediate to those exposed to UVB and those exposed to PAR only $(p<0.05)$. At most time points, the number of beads per sea urchin varied in the following pattern: PAR + UVA + UVB $>$ PAR + UVA $>$ PAR = Dark. By 16:00 $h$, the covering response declined, so that sea urchins exposed to PAR + UVA + UVB held similar numbers of beads as sea urchins exposed to PAR + UVA and PAR alone, but still more than sea urchins held in the dark $(p<0.05)$. These results show that both UVA and UVB affect sea urchins, but that sea urchins cover themselves most extensively in response to UVB irradiance, or possibly synergistically with UVA and PAR or in response to total solar energy absorbed.

The analysis described above compared the categorical treatments, yet it is most important to know whether the sea urchins specifically varied the number of beads they held in response to PAR, UVA, or UVB intensity, which was measured across all treatments. Low levels of UVB irradiance were transmitted through the Mylar ${ }^{\circledR} \mathrm{D}$ and detectable in PAR + UVA treatments at all times. Similarly, low amounts of UVA were detected in the PAR treatment at all times. PAR irradiance varied by $88.0 \%$, UVA by $99.2 \%$, and UVB by $100 \%$ of their maximal values across treatments. This variation facilitated a comparison of the amount of covering by sea urchins with a considerable range of intensities of PAR, UVA, and UVB. These values were

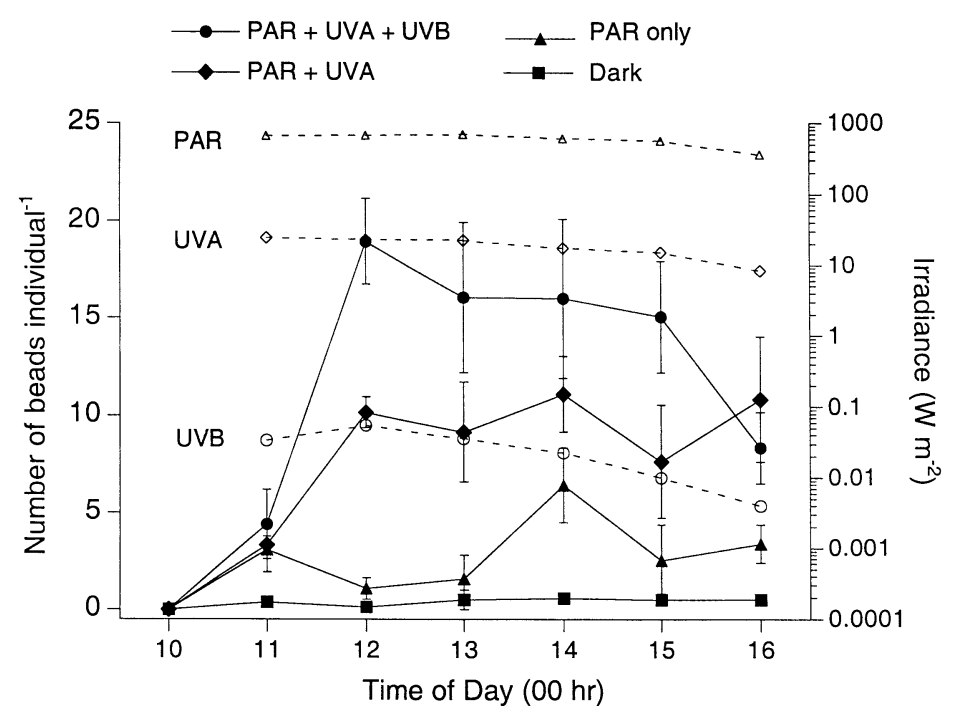

Fig. 3. Strongylocentrotus droebachiensis: The number of beads held per individual $( \pm \mathrm{SE})$ in response to light treatment over time $(\mathrm{N}=4)$. Sea urchins exposed to full sunlight (PAR + UVA+ UVB) (•) covered themselves with more beads than in all other treatments $(p>0.05$, SNK). Sea urchins that were exposed to PAR + UVA $(\diamond)$ covered themselves with significantly more beads than those exposed to PAR alone $(\boldsymbol{\Delta})$ or those held in the dark $(\boldsymbol{\square})(\mathrm{p}<0.05$, SNK $)$ 
used in the multiple regression analysis of log-transformed data, to determine whether the number of beads on sea urchins correlated with the intensity of PAR, UVA, or UVB radiation across all treatments and times. The mean number of beads held by sea urchins varied significantly with the intensity of UVB ( $p<$ $\left.0.001, \mathrm{r}^{2}=0.515\right)$ and UVA $\left(\mathrm{p}<0.001, \mathrm{r}^{2}=0.624\right)$, but not with PAR ( $\left.\mathrm{p}>0.05, \mathrm{r}^{2}=0.298\right)$. This analysis confirms that both UVB and UVA irradiance induce covering, which is moreover dose dependent.

\section{DISCUSSION}

The results demonstrate that Strongylocentrotus droebachiensis seeks shade or covers itself in response to UVR. The covering reaction is greatest when UVB is present, indicating that sea urchins are more sensitive either to the shorter, more energetic, UVB wavelengths which cause more direct damage to cellular components (Tevini 1993) or to a combination of both UVA and UVB wavelengths. These reactions are consistent with behavior of sea urchins in shallow water, but because covering by $S$. droebachiensis also occurs below the photic zone (J.-F. Hamel pers. comm.), Millot (1975) is probably correct that covering is a complex phenomenon with multiple causes. Whether this behavior in nature correlates with depth or solar irradiance has not been directly tested in the field.

Approximately $90 \%$ of the sea urchins were negatively phototactic and sought shade when exposed to UVR, whereas fewer than half of the sea urchins exposed to PAR alone sought shade. The percentage of sea urchins exposed to PAR alone that sought shade did not differ significantly from the starting point, so these individuals were neither positively nor negatively phototactic. These results agree with the UVR work of Sharp \& Gray (1962), who demonstrated that, although Arbacia punctulata is negatively phototactic and Lytechinus variegatus is positively phototactic to white light, they are both negatively phototactic to bright solar radiation. These results are also consistent with data reported that artificial light with some UVR and solar UVR evokes negative phototaxis in echinoplutei, which migrate deeper into the water column during periods of peak irradiance (Eastwood 1972, Pennington \& Emlet 1986).

It is not surprising that sea urchins avoid UVR, because long-term exposure to UVC can kill Lytechinus anemesus (Lees \& Carter 1972). Avoidance of solar UVR indicates that sea urchins also detect UVA and UVB wavelengths and avoid exposure to them (Sharp \& Gray 1962). These authors, however, did not test whether avoidance was specifically due to the UV components of sunlight or the overall intensity of light.
Thus, results presented here using UV lamps that mimic the solar spectrum (between 295 and $400 \mathrm{~nm}$ ) are important because they confirm that UV wavelengths reaching the earth induce negative phototaxis and covering response in Strongylocentrotus droebachiensis, indicating that sea urchins can detect environmentally relevant UVR and avoid it, possibly to protect themselves against UV-induced damage.

Sea urchins irradiated with artificial UVR rapidly cover themselves with artificial substrates, demonstrating that Strongylocentrotus droebachiensis senses UVR. In contrast, individuals held in the dark or exposed to PAR alone rarely placed beads on their body. Differential acquisition of beads among groups of sea urchins that had equal numbers of beads available suggests that a simple tactile response does not inducing covering. The use of inert plastic beads eliminated the possibility that covering was solely a chemically mediated feeding response.

These results are in accord with the behavior seen in Lytechinus variegatus (Sharp \& Gray 1962) and L. anamesus (Lees \& Carter 1972). Unfortunately, Lees \& Carter (1972) exposed sea urchins to unnatural UVC wavelengths (peak at $254 \mathrm{~nm}$ ) in the laboratory to examine the covering reaction. To address the problems associated with exposing sea urchins to UVC, Lees \& Carter (1972) also exposed sea urchins to artificial UVA (peak at $360 \mathrm{~nm}$ ) and verified that sea urchins cover themselves less when exposed to $360 \mathrm{~nm}$ than when exposed to $254 \mathrm{~nm}$ irradiation, but more than when held in the dark. These investigators used only dark controls and never compared their UV treatments with PAR in the laboratory or field.

Experiments using ambient solar radiation unambiguously confirm that Strongylocentrotus droebachiensis covers itself in response to UVR, particularly in response to UVB or a combination of UVB and UVA. Although the intensity of UVR and PAR radiation varied greatly over the course of the day, sea urchins that were held in darkness or exposed to PAR alone held few beads at any time, confirming that covering by $S$. droebachiensis does not vary with intensity of PAR irradiance. Previous studies demonstrated that covering changed over the course of the day and thus probably with irradiance, but they never demonstrated the independent effects of PAR versus UVR, or of specific wavebands of UVR in sunlight such as UVA versus UVB (Millott 1956, Lewis 1958, Sharp \& Gray 1962, Lees \& Carter 1972). In contrast, the present study demonstrates the effectiveness of both UVA and UVB wavelengths of natural sunlight.

Sea urchins vary the amount of covering in relation to the intensity of UVA and UVB. As the experimental design did not allow testing of the separate effects of UVA and UVB directly, multiple regression analysis 
was used to compare the effects of the intensities of UVB, UVA, and PAR independently on the amount of covering by Strongylocentrotus droebachiensis across all treatments. This type of analysis alleviates the problem of not being able to expose sea urchins to UVB separately from UVA and confirmed that UVA and UVB can independently induce the covering response, whereas PAR does not. These results explain the diurnal variation in covering response observed by others and suggest that the covering response is not controlled by a circadian rhythm (Sharp \& Gray 1962, Millot 1975). The possibility of an inherent physiological rhythm should not be overlooked, but effects of UVR are sufficiently clear to show that if such a rhythm exists it is by no means the only factor involved. In addition, there are cases where some sea urchins (e.g., S. purpuratus), do not drop their covering at night, indicating there may be multiple cues inducing covering (Douglas 1976).

Even small changes in UVB have a dramatic effect on the covering behavior in Strongylocentrotus droebachiensis, because the total irradiance of ambient UVB was approximately 50- and $10^{5}$-fold lower than UVA and PAR, respectively. Therefore, each quantum of UVB radiation (shorter, higher energy wavelengths) is much more effective at eliciting a response from these $S$. droebachiensis than longer wavelengths. These results are in keeping with generalizations that UVB is more biologically effective than UVA, which causes damage indirectly, via reactive oxygen species (Harm 1980, Tyrrell 1991). In the future, it would be useful to generate an action spectrum to examine the covering reaction by testing effects of specific wavelengths of UVR using a monochrometer, or more manageably a biological weighting function using narrow bandpass filters (Cullen \& Neale 1997). Both would bring us closer to understanding the specificity of receptors or other detection mechanisms in sea urchins which have not been identified.

It is plausible that sea urchins are sensitive to UVR and may respond differentially to wavelengths across the solar spectrum, but Lees \& Carter (1972) dismissed their results and suggest that the response to sunlight may be used as a cue that indicates the risk of displacement by surge or water motion. This conclusion is based on an assumption that 'extremely little light at less than $430 \mathrm{~nm}$ penetrates coastal water, even in the tropics' (Sverdrup et al. 1942). These investigators did not appreciate that biologically effective UVR can penetrate to at least $20 \mathrm{~m}$ in clear waters (Jerlov 1950, Fleischmann 1989) and deeply enough in coastal waters to affect subtidal sea urchins (Jerlov 1950, Smith \& Baker 1979, Lesser 1995, Booth \& Morrow 1997). Further, irradiance measurements taken at sites where these sea urchins were collected demonstrate that UVB penetrates to at least $3 \mathrm{~m}$ and UVA to $6 \mathrm{~m}$ (Adams et al. 2001). Therefore, knowing that sea urchins cover themselves in response to the UV component of sunlight specifically and determining the photoreceptors may help us understand their physiology and distribution.

Ultimately, there may be a compromise between covering and seeking shelter, two behaviors that vary among species. Similarly, morphological constraints may affect whether a sea urchin avoids UVR or covers itself. Sharp \& Gray (1962) demonstrated this point when they saw that Arbacia punctulata sought shelter and did not covered itself, whereas Lytechinus variegatus would stay in the light but cover itself. A. punctulata is unlikely to cover itself because its aboral tube feet are poorly suckered (J. Lawrence pers. comm.). Millott (1956) postulated that $L$. variegatus covers itself instead of moving to shade in order to forage in areas of bright light. Importantly, Dix (1970) demonstrated that when Evechinus chloroticus was exposed to sunlight and presented with the choice of shelter or a covering material, it usually remains in exposed areas and covered itself with algae, while those sea urchins deprived of debris seek shelter from solar radiation. Therefore, variation in covering may arise from the trade-off between shelter and foraging.

Sea urchins vary in their covering responses intraand interspecifically (Sharp \& Gray 1962, Millott 1975). Individuals may vary in their responsiveness to light. Their morphology and physiological state as well as their level of activity may affect this response in general, making intra- and interspecific comparisons inherently difficult (Millott 1975). For example, Diadema antillarum and D. setosum do not cover themselves (presumably because they have exceptionally long spines) but seek shelter during daylight hours and alter their color with the aid of melanin-containing chromatophores in response to UVR (Kleinholtz 1937, Millott \& Jacobsen 1952, Yoshida 1956,1957, Millott 1957,1975, Kristensen 1964).

Another factor that may affect the amount of covering within and among species is the presence of protective pigments or UV-screening compounds. Sharp \& Gray (1962) examined whether body color affects the covering response and suggested that color variation was perhaps one reason that the lighter Lytechinus variegatus covered itself more than did the darker Arbacia punctulata. Although these 2 species of sea urchins tend to live in slightly different microhabitats, they can co-occur within shallow waters. Moreover, they vary in their morphology, which confounds the hypothesis that the tendency for covering is associated with body color. Nevertheless, variation in the amount of pigment in the dermis of sea urchins within a species does not directly affect whether sea urchins cover 
themselves (Millott 1975). The concentration of UVabsorbing natural sunscreens, such as mycosporinelike amino acids (MAAs) found in the epidermis of sea urchins (Carroll \& Shick 1996, Karentz et al. 1997), may also affect the amount of covering. Concentrations of MAAs in the epidermis of sea urchins, however, are typically low compared with that in ovaries and eggs (Adams \& Shick 1996, 2001, Carroll \& Shick 1996, Karentz et al. 1997).

Although the present experiments did not test factors other than PAR and UVR that may induce covering, this study demonstrates for the first time that Strongylocentrotus droebachiensis specifically seeks shelter and covers itself in response to environmentally relevant wavelengths and intensities of UVR. Experiments using solar radiation show that sea urchins are exceptionally sensitive to current ambient fluences of UVR. Nevertheless, many sea urchins live subtidally, not exposed to high levels of UVR, and there may be complementary stimuli that are not mutually exclusive. UVB alone or in combination with UVA is the strongest stimulant for covering. This suggests that sea urchins may be affected by increases in UVB radiation caused by stratospheric ozone depletion. These behaviors show that sea urchins protect themselves against UVB, provided that suitable shelter is available or that materials are available to use as covering. Ultimately, these reactions to UVR may affect the distribution, health and abundance of sea urchins.

Acknowledgements. This research was supported by fellowships from the Sea Grant/Center for Marine Studies at the University of Maine and a US EPA STAR fellowship to N.L.A., and was supplemented by grants to N.L.A. from the Association of Graduate Students, University of Maine. T. Miller and R. Downs at the Darling Marine Center graciously provided field and laboratory support, which allowed these experiments to be performed. Many thanks to T. Moylan and K. Wong for technical assistance during these studies and $\mathrm{H}$. Dowse, J. Ringo, and J. True for advice about statistical analysis. I thank J. Dearborn, K. Eckelbarger, J. Lawrence, M. Lesser, J. M. Shick, R. Steneck, M. Tyler, and R. Van Beneden and an anonymous reviewer for helpful advice that improved this manuscript and Dr Hamel for unpublished observations.

\section{LITERATURE CITED}

Adams NL, Shick JM (1996) Mycosporine-like amino acids provide protection against ultraviolet radiation in eggs of the green sea urchin Strongylocentrotus droebachiensis. Photochem Photobiol 64:149-158

Adams NL, Shick JM (2001) Mycosporine-like amino acids prevent UVB-induced abnormalities during early development of the green sea urchin Strongylocentrotus droebachiensis. Mar Biol 138:267-280

Adams NL, Shick JM, Dunlap WC (2001) Selective accumulation of mycosporine-like amino acids in ovaries of the green sea urchin, Strongylocentrotus droebachiensis, is not affected by ultraviolet radiation. Mar Biol 138:281-294 Boone L (1925) Echinodermata from tropical East American seas. Bull Bingham Oceanogr Col 1:1-22

Booth CR, Morrow JH (1997) The penetration of UV into natural waters. Photochem Photobiol 65:254-257

Carroll AK, Shick JM (1996) Dietary accumulation of UVabsorbing mycosporine-like amino acids (MAAs) by the green sea urchin (Strongylocentrotus droebachiensis). Mar Biol 124:561-569

Clouse R (1997) Burying behavior in an Indo-Pacific sea cucumber; Bohadschia marmarata Jaeger (Holothuroidea): a circadian, not circatidal rhythm. Micronesica 30: $245-257$

Cullen JJ, Neale PJ (1997) Biological weighting functions for describing the effects of ultraviolet radiation on aquatic systems In: Häder DP (ed) The effects of ozone depletion on aquatic ecosystems. Academic Press, San Diego, p 97-118

Dambach M, Henschel G (1970) Die Reaktion der Chromatophoren des Seeigels Centrostesphanus longispinus auf Licht. Z Ver Physiol 64:400-406

Dayton PK, Robillard GA, Paine RT (1970) Benthic faunal zonation as a result of anchor ice at McMurdo Sound, Antarctica. In: Holdgate MW (ed) Antarctic ecology, Vol 1. Academic Press, London, p 244-258

Dix TG (1970) Covering response of the echinoid Evechinus chloroticus (Val.). Pac Sci 24:187-194

Douglas CA (1976) Availability of drift material and the covering response of the sea urchins Strongylocentrotus purpuratus (Stimpson). Pac Sci 30:83-89

Dubois R (1914) Action de la lumiere sur les Echinoderms. Comp Rend Int Congr Zool 9:148

Dykens JA, Shick JM (1984) Photobiology of the symbiotic sea anemone, Anthopleura elegantissima: defenses against photodynamic effects and seasonal photoacclimatization. Biol Bull 167:683-697

Eastwood JLJ (1972) The development and photic behavior of Lytechinus variegatus echinoplutei larvae. Doctoral dissertation, Lehigh University, Bethlehem, PA

Fleischmann EM (1989) The measurement and penetration of ultraviolet radiation into tropical marine waters. Limnol Oceanogr 34:1623-1629

Gulko D, Lesser MP, Ondrusek M (1995) Introduction to materials and methods commonly used by participants in the 1994 HIMB Summer Program on 'UV Radiation and Coral Reefs'. In: Gulko D, Jokiel PL (eds) Ultraviolet radiation and coral reefs. University of Hawaii, Sea Grant Tech Rep No. 41, Honolulu, p 19-24

Harm W (1980) Biological effects of ultraviolet radiation. Cambridge University Press, Cambridge

Holmes SJ (1912) Phototaxis in the sea urchin, Arbacia punctulata. J Anim Behav 2:126-136

Jerlov NG (1950) Ultra-violet radiation in the sea. Nature 166: 111-112

Karentz D, Dunlap WC, Bosch I (1997) Temporal and spatial occurrence of UV-absorbing mycosporine-like amino acids in tissues of the antarctic sea urchin Sterechinus neumayeri during springtime ozone-depletion. Mar Biol 129:343-353

Kirk JTO (1994) Light and photosynthesis in aquatic ecosystems, 2nd edn. Cambridge University Press, Cambridge

Kleinholz LH (1937) Color changes in echinoderms. Pubbl Stn Zool Napoli 17:1-5

Kristensen I (1964) The effect of raising Diadema at different levels of light intensity on pigmentation and preference for darkness. Caribb J Sci 4:441-443

Lees DC, Carter GA (1972) The covering response to surge, 
sunlight, and ultraviolet light in Lytechinus anamesus (Echinoidea). Ecology 53:1127-1133

Lesser MP (1995) General overview of instrumentation, experimental methods, and attenuation of UV radiation into natural waters. In: Gulko D, Jokiel PL (eds) Ultraviolet radiation and coral reefs. University of Hawaii, Sea Grant Tech Rep No. 41, Honolulu, p 13-14

Lewis JB (1958) The biology of the tropical sea urchins Tripneustes esculentus Leske in Barbados, British West Indies. Can J Zool 36:607-621

Lindahl E, Runnström J (1929) Variation und okologie von Psammechinus millaris (Gmelin). Acta Zool 10:401-484

Madronich S, McKenzie R, Bjorn L, Caldwell M (1998) Changes in biologically active ultraviolet radiation reaching the Earth's surface. In: van der Leun JC, Tang X, Tevini M (eds) Environmental effects of ozone depletion: 1998 assessment. United Nations Environment Programme Report, Elsevier Science, Lausanne, p 5-19

McCree KJ (1983) Photosynthetically active radiation. In Lange OL, Nobel PS, Osmond CB, Ziegler H (eds) Physiological plant ecology I. Springer Verlag, New York, p 41-55

Milligan HN (1915) Observations on the foreign objects carried by the purple-tipped sea urchin. The Zoologist 19: 441-453

Millott N (1955) The covering reaction in a tropical sea urchin. Nature 175:561

Millott N (1956) The covering reaction of sea-urchins. I. A preliminary account of covering in the tropical echinoid Lytechinus variegatus (Lamarck), and its relation to light. J Exp Biol 33:508-523

Millott N (1957) Napthaquinone pigment in the tropical seaurchin, Diadema antillarum Phillipi. Proc Zool Soc Lond 129:263-272

Millott N (1975) The photosensitivity of echinoids. In: Russell FS, Yonge M (eds) Advances in marine biology. Academic Press, New York, p 1-52

Millott N, Jacobson FW (1952) The occurrence of melanin in the sea-urchin, Diadema antillarum Philippi. J Invest Dermatol 91-95

Moore HB, Jutare T, Jones JA, McPherson BF, Roper CF

Editorial responsibility: John Lawrence (Contributing

Editor), Tampa, Florida, USA
(1963) A contribution to the biology of Tripneustes esculentus. Bull Mar Sci 13:267-281

Mortensen Th (1943) A monograph of the Echinoidea, Vol III.2. Reitzel, Copenhagen

Orton JH (1929) On the occurrence of Echinus esculentus on the foreshore in the British Isles. J Mar Biol Assoc UK 16: 289-296

Pennington J, Emlet RB (1986) Ontogenetic and diel vertical migration of a planktonic echinoid larvae, Dendraster excentricus (Eschscholtz): occurrence, causes, and probable consequences. J Exp Mar Biol Ecol 104:69-95

Péquigant E (1966) 'Skin digestion' and epidermal absorption in irregular and regular urchins and their probably relation to the outflow of spherule-coelomocytes. Nature 210: 397-399

Sharp DT, Gray IE (1962) Studies on factors affecting the local distribution of two sea urchins, Arbacia punctulata and Lytechinus variegatus. Ecology 43:309-313

Smith RC, Baker KS (1979) Penetration of UV-B and biological effective dose-rates in natural waters. Photochem Photobiol 29:311-323

Sverdrup HU, Johnson MW, Fleming RH (1942) The oceans: their physics, chemistry, and general biology. Prentice Hall, Inc, New York

Tevini M (1993) Molecular biological effects of ultraviolet radiation. In: Tevini $M$ (ed) UV-B Radiation and ozone depletion: effects on humans, animals, plants, microrganisms, and materials. Lewis Publishers, Boca Raton, FL, p $1-16$

Tyrrell RM (1991) UV-A (320-380 nm) radiation as an oxidative stress. In: Sies H (ed) Oxidative stress: oxidants and antioxidants. Academic Press, San Diego, p 57-83

von Uexküll J (1887) Ueber Reflexe bei den Seeiglen. Z Biol 34:298-318

Yoshida M (1956) On the light response of the chromatophores of the sea urchin Diadema setosum. (Leske). J Exp Biol 33:119-123

Yoshida M (1957) Spectral sensitivity of chromophores in Diadema setosum (Leske). J Exp Biol 34:222-225

Zar JH (1999) Biostatistical analysis, 4th edn. Prentice Hall, Englewood Cliffs, NJ, p 413-451

Submitted: May 1, 2000; Accepted: November 23, 2000 Proofs received from author(s): March 5, 2001 